\title{
Building health literacy in a Polish region: protocol for the POWER project in Lower Silesia
}

\author{
Kinga Janik-Koncewicz ${ }^{1,2}$, Aleksandra Herbeć ${ }^{1}$, Mateusz Zatoński ${ }^{1}$, Katarzyna Rosik ${ }^{1}$ Iwona Młoźniak ${ }^{1}$,

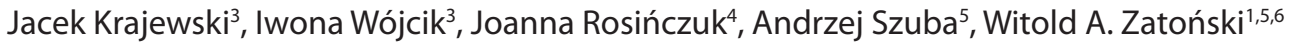 \\ ${ }^{1}$ Health Promotion Foundation, Nadarzyn, Poland \\ ${ }^{2} \mathrm{PhD}$ Candidate, University of Aberdeen, UK \\ ${ }^{3}$ Lower Silesian Association of Family Doctors - Employers, Wroclaw, Poland \\ ${ }^{4}$ Division of Nervous System Diseases, Faculty of Health Sciences, Wroclaw Medical University, Poland \\ ${ }^{5}$ Division of Angiology, Faculty of Health Sciences, Wroclaw Medical University, Poland \\ ${ }^{6}$ European Observatory of Health Inequalities, State University of Applied Sciences, Kalisz, Poland
}

\begin{abstract}
There is a high prevalence of premature mortality and unhealthy lifestyle behaviours in Lower Silesia in Poland (regional capital is the city of Wroclaw). One plausible reason is low health literacy among this population. Health literacy is one of the most important elements of public health and health promotion endeavours. It can be conceptualised as abroad range of cognitive and social skills as well as knowledge needed by an individual to maintain good health, prevent or manage diseases, and effectively engage with healthcare professionals and resources. The Health Promotion Foundation (HPF), in collaboration with regional institutions and organisations, initiated in 2017 a broad initiative to improve health in this region. The overarching aim of the wider programme is to improve the quality of care among primary care patients. The project stream led by HPF aims to improve knowledge and health-related competences in the population of primary care patients in Lower Silesia. It involves (1) needs assessment based on the analysis of data on health status and neds from 50 participating primary care clinics, followed by (2) development of tailored face-to-face workshops that will be delivered by trained public health students, (3) who will be mentored using train-the-trainer approach. It is anticipated that the project will impact on three main areas in the long term. First, it will lead to creation of a package of workshops that could be delivered to other primary care patients. Second, it will create opportunities for students majoring in public health in the region to become directly involved in activities focused on health education and promotion. Three, it is anticipated that the project will lead to improvements in health and wellbeing among the participating patient groups. The present report describes the scope and method of the project.
\end{abstract}

KEY WORDS: health literacy, premature mortality, Lower Silesia population, health improvement.

ADDRESS FOR CORRESPONDENCE: Kinga Janik-Koncewicz, Health Promotion Foundation, 51 Mszczonowska Street, 05-830 Nadarzyn, Poland, phone: +48 2237800 22, e-mail: biuro@promocjazdrowia.pl

\section{INTRODUCTION}

Health is one of the most important factors determining the quality of human life, both in the social and individual dimension. Health indicators (e.g. life expectancy or premature mortality) are therefore key elements in estimating socio-economic development in every community. One of the measures that incorporate the importance of good health for societies is the Human Development Index (HDI) (see On ageing, economization of health, and media ethics: how much is a month of life worth?, pp. 9-12) [1].

The health situation in different parts of Europe is dramatically diverse [2]. This is evidenced by one of the fundamental health indicators - premature mor- 


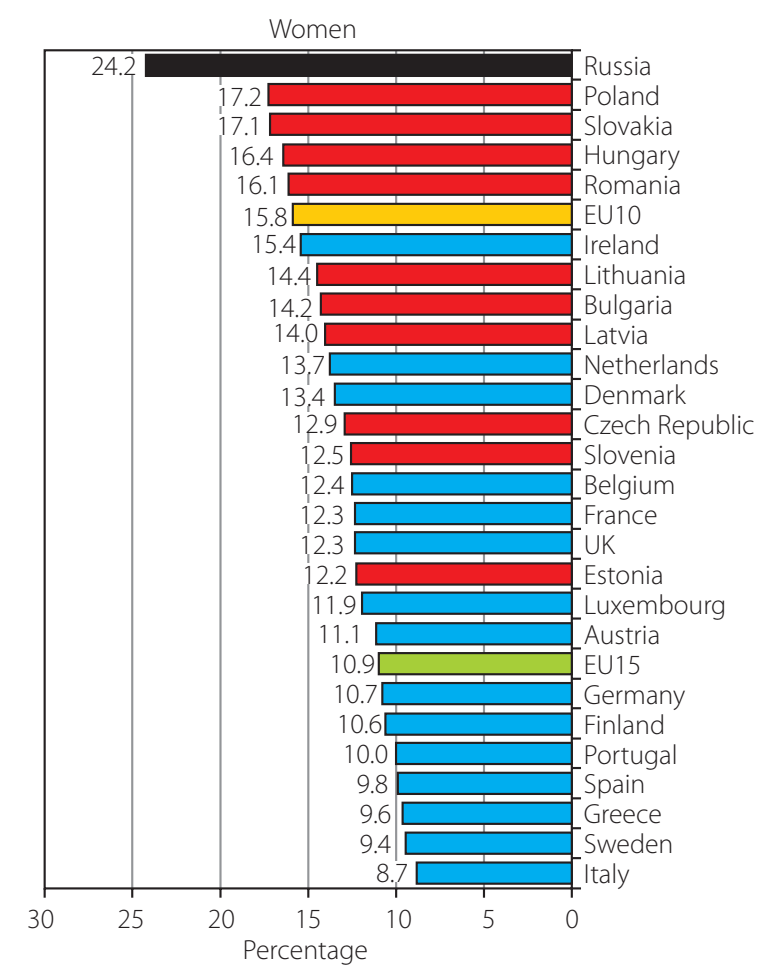

FIG. 1. Percentage of deaths before 65 years, 2014

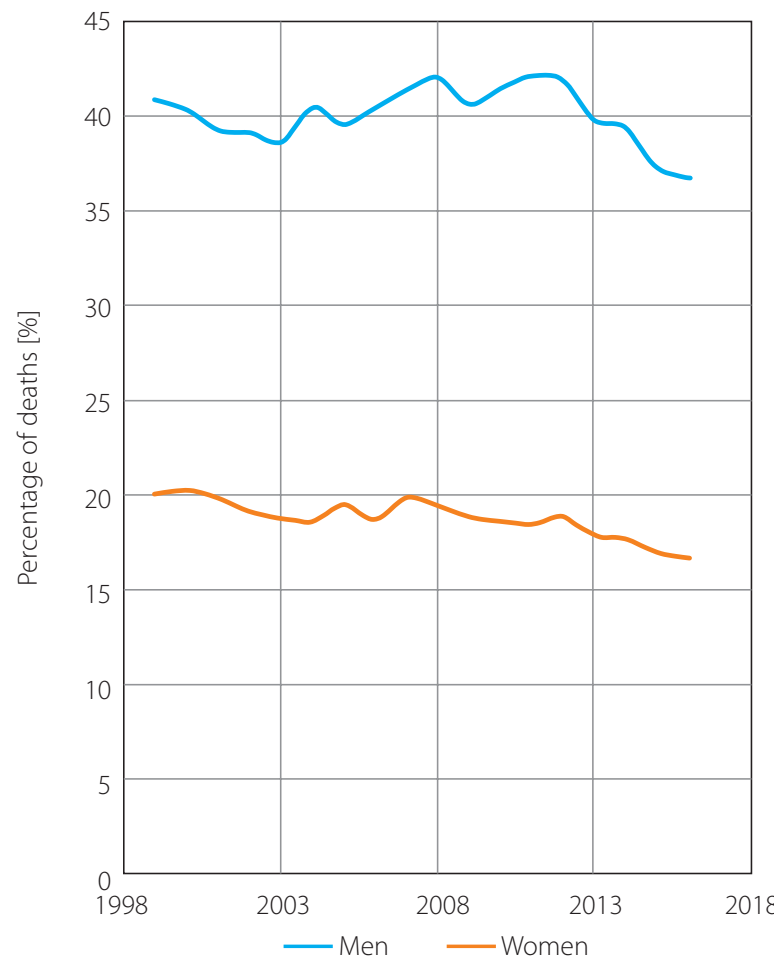

FIG. 2. Percentage of deaths before 65 years in Lower Silesia

tality $^{1}$. Premature mortality is a measure of unfulfilled life expectancy. In most developed countries of Europe (see Fig. 1 for details), the percentage of deaths before

${ }^{1}$ The best epidemiological measures of premature mortality are: probability
of dying between $0-64$ years of age, and percentage of deaths before age of 65 years.

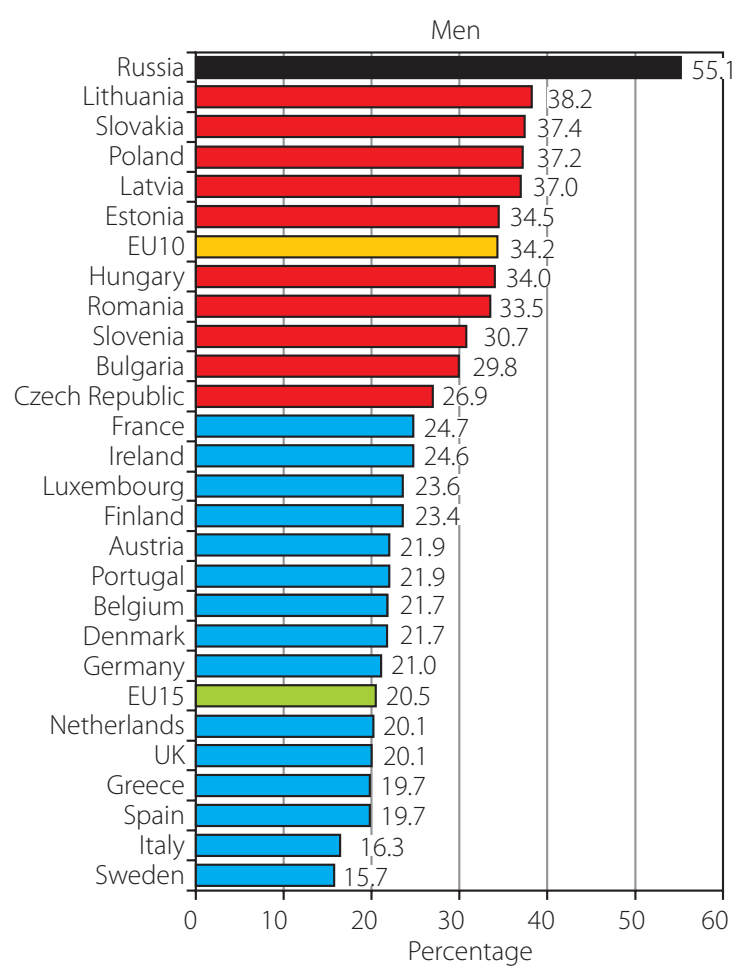

65 years of age is very low. For example, among Western European women its averaged was a little over $10 \%$. This contrasts premature mortality rates in many Eastern European member states of the European Union, as well as in Russia, where in 2014 55\% of men died before reaching 65 years of age. In Poland, the percentage of deaths before 65 years of age in 2014 stood at 37\% in men and $17 \%$ in women, and was one of the highest rates in the European Union. Similarly, in Lower Silesian region of Poland, in the beginning of second decade of $21^{\text {st }}$ century more than $40 \%$ of men and nearly $20 \%$ of women have died before 65 years (Fig. 2). Eliminating this huge health disparity within Europe should be treated as a matter of public health priority.

Premature mortality is determined by multiple factors. Among the most important, yet still often neglected, are lifestyle factors that influence human body, i.e. it's chemical, physical, and biological qualities, which includes smoking, drinking alcohol, bad nutritional habits, and lack of physical activity.

\section{POPULATION HEALTH IN LOWER SILESIA}

Lower Silesia is a region in southwestern Poland, bordering Czech Republic and Germany, with a population around 3 million people. Its regional capital is the city of Wrocław.

According to the results of the 2014 Polish National Health Survey [3] around $94 \%$ of men and $86 \%$ of women in Lower Silesia had appraised their health status as good or very good, despite that fact that as many as $54 \%$ of men and $60 \%$ of women suffered from chronic diseases 
(i.e. hypertension, CVD, diabetes, cancer and other). Sixty percent of men and $45 \%$ of women in Lower Silesia had excessive weight $\left(\mathrm{BMI} \geq 25.0 \mathrm{~kg} / \mathrm{m}^{2}\right)$. Almost a third of the population did not at fruits and vegetables at least once a day. Around $34 \%$ of men and $22 \%$ of women smoked tobacco, and $82 \%$ of men and $64 \%$ of women drunk alcohol. Additionally, only $1.3 \%$ of the Lower Silesian population vaccinated against flu in last year (the national average for Poland in 2017 was 3.7\%, compared to $62 \%$ in the UK [4]).

It is clear that there is ample room for improvement of health behaviours in Lower Silesia. In achieving this it is crucial to increase the knowledge of its population on risk factors and healthy lifestyles. The Health Promotion Foundation, in collaboration with local institutions, has launched a range of initiatives which can help strengthen the public health situation in the region through building greater health literacy among its inhabitants.

\section{WHAT IS HEALTH LITERACY?}

The concept of health literacy first appeared in research literature in the 1980s and 1990s. Most generally, it covers the broad range of competencies, as well as cognitive and social skills needed by an individual to maintain good health, prevent or manage disease, and engage effectively with relevant health resources and information. Some researchers use the "health literacy" concept to determine communication between medical doctors, medical personnel and patients and to ensure better understanding and carry out prescribed treatment [5]. The classical definition of health literacy comes from Ilona Kickbush, who in the late 1990s described it as the information and knowledge on health, the understanding of social components of health, the skills necessary to negotiate with environment understanding and weighting risk of individual and social behaviours, coping abilities, carrying abilities, using available health services and implementing health knowledge [6]. However, defining health literacy precisely is difficult. Polish scholars also had their input in research on health literacy $[2,7,8]$. The Health Promotion Foundation for decades has been focused on health literacy research as well, especially in area of tobacco smoking in Poland, but also other health behaviours $[2,9,10]$.

Definitions of health literacy have evolved since the 1990s and today the World Health Organisation guidelines describe it as the broad set of skills needed by an individual to understand and use information in way which keeps themselves, their families, and their communities, in good health [11]. This requires the achievement of a level of knowledge, personal skills, and self-confidence necessary for an individual to undertake lifestyle changes promoting good health. For example, thanks to improved health literacy, people would be able not only to understand a leaflet or take medications according to prescription, but also to undertake more assertive activities and take the initiative in caring for their health.

Limited health literacy is linked with unhealthy lifestyle behaviours; i.e. bad nutritional habits, alcohol consumption, lack of physical activity, smoking; and with increased risk of premature mortality and hospitalization $[12,13]$. The basis to increase health literacy is health education and skill training, especially in adopting healthy lifestyles, effectively engaging with treatment and healthcare providers, and actively engaging with self-care [14].

\section{HEALTH PROMOTION FOUNDATION AND THE POWER PROJECT}

In Poland health literacy remains a little known and rarely used concept. In 2017 the Health Promotion Foundation joined a collaboration with two organizations of medical doctors (the Lower Silesian Association of Family Doctors - Employers and the Association "Employers of Health”) in the project entitled „Healthy company, healthy people - improving quality in primary care". The project has been financed by the European Social Fund within the Operational Programme Knowledge Education Development (grant number WNDPOWR.05.02.00-00-0019/17), shortened to POWER. The intermediary institution overseeing the programme is the Polish Ministry of Health.

\section{PROGRAMME AIMS AND SCOPE}

The overall long-term aim of the programme is community health development in Lower Silesia region through the improvement of the quality of primary care though improving health literacy among patients and clinicians. The programme has three streams, or projects: (1) improving health literacy and health-related competencies in the population of primary care patients (led by HPF; reported in detail in this report), (2) development of primary care settings personnel (led by the Association "Employers of Health"), and (3) improving collaboration between primary and secondary care clinicians, including preparing the platform for communication (led by the Lower Silesian Association of Family Doctors - Employers). The Programme activities will involve staff and patients of 50 primary care settings in the region.

\section{PROJECT METHODS}

The current project led by HPF aims to improve health literacy and knowledge among the primary care doctors and patients in Lower Silesia, which will involve developing and organisation of student-led group health education workshops for patients from 50 primary care settings. The project has three phases: (1) needs assessment and development, (2) implementation, and (3) evaluation.

During phase one three prevention workshop packages will be developed, which will be delivered by trained 
students during phase two. The workshop content will be based on (i) the analysis of data on health services provided by the participating primary care settings and which are reported to the National Health Fund, (ii) research and evidence in public health and behaviour change, and (iii) in consideration of the health priorities of the Lower Silesian region. According to preliminary assumptions, programmes will cover knowledge relevant to the principal chronic non-communicable diseases and the risk factors that are linked to them, as well as relevant health literacy competencies, such as communicating with healthcare professionals, and identifying relevant information and support.

In the second, implementation, phase of the project, workshops for medical doctors and other healthcare providers will be organised. These workshops will focus not only on knowledge of primary and secondary prevention, but will also help develop communication kills with patients and motivational dialogue methods intended to build health literacy. Furthermore, one of the innovative elements of the POWER project is the engagement of public health students from the Faculty of Health Sciences of the Wroclaw Medical University through train-thetrainer model. The students will be recruited and trained to carry out the developed educational workshops for patients. This 'training of the trainers' method will help to broaden the reach of the project and to conduct workshops in multiple primary care settings. Additionally, after the POWER project completion, it will help assure the continuation of the initiative by the next generations of students.

The last phase of the project will include its evaluation, monitoring visits, and preparing a summary of results, which will be used to undertake similar activities in the future.

\section{CONCLUSIONS}

The presented project is a pioneering initiative, based on collaboration with primary care doctors and medical university students specialised in public health, aimed at raising knowledge and building health behaviours in population of Lower Silesia. It is a pilot study. It is expected that after careful evaluation the project will result in development of a model for comprehensive activities to build health competences in different regions of Poland.

\section{ACKNOWLEDGEMENT}

The project has been financed by the European Social Fund within the Operational Programme Knowledge Education Development (grant number WNDPOWR.05.02.00-00-0019/17). The intermediary institution overseeing the programme is the Polish Ministry of Health.

\section{DISCLOSURE}

The authors declare no conflicts of interest.

\section{References}

1. Human Development Index (HDI). United Nations Development Programme. Human Development Reports. Available from: http://hdr.undp.org/en/content/human-development-index-hdi (accessed: 5 March 2018).

2. Zatoński W and the HEM project team. Closing the health gap in European Union. Cancer Center and Institute, Warsaw 2008.

3. Central Statistical Office. Health status of population in Poland in 2014. Statistical Information and Elaborations. Central Statistical Office, Warsaw 2016.

4. Seweryn M, Leśna M.Szczepienia przeciwko grypie w państwach europejskich. Raport [Report on vaccination against flu in European countries]. Econmed, 2017.

5. Pleasant A, Kuruvilla S. A tale of two health literacies: public health and clinical approaches to health literacy. Health Promot Int 2008; 23: 152-159.

6. Kickbush I. Think health: what makes the difference? Health Promot Int 1997; 12: 265-272.

7. Sorensen K, Van den Broucke S, Fullam J, et al., for (HSL-EU) Consortium Health Literacy Project European. Health literacy and public health: a systematic review and integration of definitions and models. BMC Public Health 2012; 12: 80.

8. Sorensen K, Van den Broucke S, Pelikan JM, et al., on behalf of the HSL-EU Consortium. Measuring health literacy in populations: illuminating the design and development process of the European Health Literacy Survey Questionnaire (HLS-EU_Q). BMC Public Health 2013; 13: 948.

9. Zatoński W. Jak rzucić palenie. Profesor Witold Zatoński radzi. [How to quit smoking. Professor Witold Zatoński advises]. Medycyna Praktyczna, Kraków 2007.

10. Zatoński W, Janik K. Mini poradnik. Dbaj o zdrowie. Jedz 5 razy dziennie warzywa i owoce [Miniguide. Take care of your health. Eat 5 a day fruit and vegetable]. Fundacja „Promocja Zdrowia”, Warszawa 2003.

11. World Health Organization. The mandate for health literacy. Available from: http://www.who.int/healthpromotion/conferences/9gchp/health-literacy/en/(accessed: 5 March 2018).

12. Berkman ND, SheridanSL, Donahue KE, et al. Low health literacy and health outcomes: an updated systematic review. Ann Intern Med 2011; 155: 97-107.

13. Dewalt DA, Berkman ND, Sheridan S, et al. Literacy and health outcomes: a systematic review of the literature. J Gen Intern Med 2004; 19: 1228-1239.

14. Paasche-Orlow MK, Wolf MS. The causal pathways linking health literacy to health outcomes. Am J Health Behav 2007; 31: S19-S26.

\section{AUTHOR'S CONTRIBUTIONS}

KJK and WZ preparade the concept and the first version of the publication. All authors contributed to the final version of the publication. 